УДК $338.46+640.4$

РАЗВИТИЕ РЫНКА ХОСТЕЛОВ КАК ПЕРСПЕКТИВНОЕ НАПРАВЛЕНИЕ МАЛОГО БИЗНЕСА Ирина В. Такмашева ${ }^{a,{ }^{(I D}}$; Сергей Г. Тяглов ${ }^{b}$

${ }^{a}$ Югорский государственный университет, 628012, Россия, г. Ханты-Мансийск, ул. Чехова, 16

${ }^{b}$ Ростовский государственный экономический университет, 344002, г. Ростов-на-Дону, ул. Большая Садовая, 69

@I_Takmasheva@ugrasu.ru

ID https://orcid.org/0000-0002-7422-2744

Поступила в редакиию 03.11.2018. Принята к печати 26.11.2018.

Ключевые слова: гостиничный бизнес, конкуренция, ценообразование, туризм, услуги

\begin{abstract}
Аннотация: Исследован рынок хостелов г. Ханты-Мансийска с точки зрения одного из перспективных направлений малого бизнеса. Объектом настоящего исследования является рынок гостиничного бизнеса Ханты-Мансийска. Главная цель исследования заключается в выработке практических рекомендаций по открытию хостелов в Ханты-Мансийске. Для достижения поставленной цели были изучены следующие проблемные вопросы: зарубежный опыт развития рынка хостелов, оценка спроса и предложения услуг гостиничного бизнеса Ханты-Мансийска, ценообразование на рынке гостиничных услуг, деловой климат для развития рынка хостелов. В исследовании использованы методы статистического и сравнительного анализа, специальные методы экономического анализа, а также метод стратегического планирования SWOT-анализ. В результате нами сформулированы предложения по открытию хостелов в Ханты-Мансийске. Представленные рекомендации могут быть использованы предпринимателями, осуществляющими деятельность в сфере гостиничного бизнеса на территории Ханты-Мансийска. Предложения могут быть полезны администрации города Ханты-Мансийска при разработке стратегии социально-экономического развития муниципального образования.
\end{abstract}

Для цитирования: Такмашева И. В., Тяглов С. Г. Развитие рынка хостелов как перспективное направление малого бизнеса // Вестник Кемеровского государственного университета. Серия: Политические, социологические и экономические науки. 2018. № 4. С. 137-144. DOI: 10.21603/2500-3372-2018-4-137-144

\section{Введение}

Рынок гостиничного бизнеса представляет на сегодня особенный интерес в связи с углублением диверсификации сферы услуг в Югре. В соответствии со Стратегией социально-экономического развития Ханты-Мансийского автономного округа - Югры до 2020 г. и на период до 2030 г., утвержденной распоряжением Правительства Ханты-Мансийского автономного округа - Югры от 22.03.2013 № 101-рп, в систему приоритетов долгосрочного социально-экономического развития ХантыМансийского автономного округа входит развитие въездного туризма как наиболее перспективного потребительского сегмента.

По мнению отечественных исследователей, в России рынок частного сектора размещения только формируется и не обеспечен достаточной правовой базой. Тем не менее темпы его развития в настоящее время одни из самых высоких в мире [1]. Некоторые ученые считают, что базовым ресурсом выстраивания позитивного имиджа отдельной территории мо- жет выступать не столько экономический капитал, сколько символический капитал места [2]. Другие придерживаются мнения, что высокий уровень социально-экономического развития региона возможен только при реализации кластерного взаимодействия государственных и бизнес-структур [3].

По оценкам экспертов, в ближайшем будущем востребованными станут такие виды туризма, как культурно-познавательный, этнографический, событийный, зимний, экологический, медицинский, конгрессно-выставочный. Успешная продажа туристских продуктов требует доверительных взаимоотношений между клиентами и продавцами, поэтому, по мнению ряда исследователей, важное значение приобретает репутация туроператоров, отелей и авиакомпаний [4]. Основой для увеличения потока въездных туристов станет строительство важнейших туристических объектов нового уровня: мини-гостиниц и хостелов. Таким образом, глобальные тенденции и возникающие проблемы меняют гостиничный бизнес. Изменение 
структуры клиентских потоков подталкивает как минимум к двум очевидным утверждениям: к повышению уровня и индивидуализации сервиса [5].

Хостелы имеют большие перспективы для развития и укрепления на рынке, поскольку они обладают высокой социально-экономической эффективностью [6]. Одной из современных тенденций является изменение статуса хостела, который превращается в удобное средство размещения не только для бюджетных путешественников, но и для деловых людей [7]. Учитывая это, особенно актуальным становится развитие рынка хостелов на территории северных регионов России, в которых трудоспособное население осуществляет свою деятельность в основном вахтовым и сезонным методом.

Некоторые отечественные исследователи поднимают проблему развития детско-юношеских хостелов, которые могут играть важную роль в обеспечении единого образовательного пространства России, выступая в качестве площадок для организации образовательных, творческих и спортивных мероприятий на уровне региона или страны [8]. Другие исследователи рассматривают хостелы с точки зрения социальных гостиниц как коллективных средств размещения, предназначенных для временного пребывания туристов, в первую очередь, из малообеспеченных слоев населения [9].

Развитие рынка хостелов исторически связано с европейской цивилизацией, а именно с Англией. Хостел переводится с английского как общежитие и представляет собой европейскую систему размещения, в соответствии с которой постояльцам на короткий или длительный период времени предоставляется жилье в виде спального места без дополнительных удобств в помещении. Аналогом хостела в России можно считать так называемые русские доходные дома, которые располагались у трактиров, чтобы путешественникам не приходилось искать место ночлега [10]. В соответствии с ГОСТ Р 56184-2014 «Услуги средств размещения: общие требования к хостелам», введенным в действие приказом Федерального агентства по техническому регулированию и метрологии от 23.10.2014 № 1393-ст, хостелом является экономичное средство размещения, предназначенное для временного проживания, преимущественно для малобюджетного туризма, имеющее номера или комнаты различной вместимости и санузлы, как правило, за пределами номера или комнаты, а также помещения (зоны, места) для общения гостей.

Анализ рынка гостиничных услуг на примере муниципального образования г. Ханты-Мансийска

Рынок предприятий гостиничного бизнеса представляет собой систему экономических отношений между предприятиями сферы гостиничного бизнеса и потребителями услуг, в результате которых взаимоувязываются различные интересы поставщиков услуги и потребителей. При оценке рынка гостиничных услуг, на наш взгляд, необходимо учитывать следующие параметры:

1) объектом купли-продажи на рынке гостиничного бизнеса являются услуги;

2) спрос на гостиничные услуги отличается рядом особенностей и варьируется в зависимости от материальных возможностей потребителя услуги, возраста, ценностей, мотивов, иных экономических и социальных факторов;

3) предложение рынка гостиничных услуг, как правило, является многообразным и подразделяется на типы размещения, ценовые факторы, а также в зависимости от качества предоставляемых услуг.

По состоянию на 01.04.2018 на территории муниципального образования г. Ханты-Мансийска рынок хостелов представлен 8 малыми предприятиями, из которых 2 хостела (гостиница «СДЮШОР» и гостиница «Эконом-класс») являются специализированными и ориентированы на предоставление услуг по размещению преимущественно спортсменов в период проведения спортивных мероприятий в г. Ханты-Мансийске (таблица $1^{1}$ ).

Для организации хостелов важными факторами являются, прежде всего, структура низких издержек и соответствующая им ценовая политика [11]. Цена гостиничного номера зависит от множества факторов и устанавливается с учетом себестоимости содержания номера, соотношения спроса и предложения, цен конкурентов, имиджа предприятия сферы услуг. В себестоимость включаются материальные затраты, оплата труда обслуживающего персонала, амортизация основных средств, прочие расходы (содержание аппарата управления, стоимость аренды зданий и помещений, оборудования и инвентаря, обслуживание технических средств управления, средств сигнализации, охраны). Цена номера или места в номере устанавливается, как правило, за его использование в течение 1 суток, в некоторых хостелах применяется почасовая оплата. Ценовую политику предприятия определяет служба маркетинга. В случае, если на предприятии такая служба отсутствует, такие услуги оказывают специализированные организации, предоставляющие консалтинговые услуги, в том числе в сфере маркетинга. Указанные специалисты рассчитывают среднюю цену номера в гостинице, характеризующую наиболее точно положение гостиничного предприятия на рынке услуг с точки зрения доступности для различных сегментов потребительского рынка.

\footnotetext{
${ }^{1}$ Составлено авторами на основании данных Туристско-информационного центра Ханты-Мансийска. Режим доступа: http://visithm.ru (дата обращения: 01.04.2018).
} 
Таблица 1. Анализ хостелов города Ханты-Мансийска по параметрам: категория номеров, минимальная стоимость, предоставляемые услуги

Table 1. Analysis of Khanty-Mansiysk hostels by parameters: room category, minimum cost, services provided

\begin{tabular}{|c|c|c|c|c|}
\hline Краткое описание & $\begin{array}{c}\text { Категория } \\
\text { номеров }\end{array}$ & $\begin{array}{c}\text { Минимальная } \\
\text { стоимость } \\
\text { номера }\end{array}$ & $\begin{array}{c}\text { Услуги, входящие } \\
\text { в соимость номера }\end{array}$ & $\begin{array}{c}\text { Дополнительные } \\
\text { услуги }\end{array}$ \\
\hline
\end{tabular}

Гостиница «СДЮШОР», ул. Калинина, 1. Гостиница находится недалеко от центра города в 10 минутах ходьбы от Гостиного двора

\begin{tabular}{|l|l|l|l|l|}
\hline $\begin{array}{l}\text { гостиница эконом-класса, } \\
\text { ориентированная на } \\
\text { размещение спортсменов } \\
\text { в период проведения } \\
\text { спортивных мероприятий } \\
\text { в Ханты-Мансийске }\end{array}$ & $\begin{array}{l}\text { двухестные, } \\
\text { трехместные, } \\
\text { четырехместные }\end{array}$ & $\begin{array}{l}390 \text { руб. / } \\
\text { сутки }\end{array}$ & $\begin{array}{l}\text { телевизор, холодиль- } \\
\text { ник }\end{array}$ & $\begin{array}{l}\text { вызов такси, } \\
\text { ксерокс, факс, } \\
\text { медкабинет, } \\
\text { парикмахерская, } \\
\text { кафе, открытая } \\
\text { спортивная } \\
\text { площадка, } \\
\text { беговая дорожка, } \\
\text { лыжная трасса }\end{array}$ \\
\hline
\end{tabular}

Хостел «Черемушкин Лог», ул. Объездная, 39/2. Расположен недалеко от «Археопарка», Биатлонного центра, Ледового Дворца, Аквапарка

\begin{tabular}{|c|c|c|c|c|}
\hline $\begin{array}{l}\text { к услугам гостей } 16 \text { номе- } \\
\text { ров, оборудованых } \\
\text { кабельным телевидением } \\
\text { с цифровым качеством, } \\
\text { высокоскоростным } \\
\text { Интернетом }\end{array}$ & $\begin{array}{l}\text { трехместные, } \\
\text { пятиместные }\end{array}$ & $\begin{array}{l}750 \text { руб. / } \\
\text { сутки }\end{array}$ & $\begin{array}{l}\text { телевизор с кабель- } \\
\text { ными каналами } \\
\text { (40 каналов), безли- } \\
\text { митный Интернет, } \\
\text { охраняемая парковка, } \\
\text { бесплатные горячие } \\
\text { напитки (чай, кофе), } \\
\text { зона отдыха с } \\
\text { мангалом, бесплат- } \\
\text { ный трансфер } \\
\text { аэропорт / автовок- } \\
\text { зал - гостиница и } \\
\text { обратно, обзорная } \\
\text { экскурсия по городу }\end{array}$ & отсутствуют \\
\hline
\end{tabular}

Гостиница «Светлая», ул. Светлая, 24. Гостиница находится в 3 км от центра города и в 5 км от аэропорта \begin{tabular}{|l|l|l|l|l} 
к услугам гостей 22 ком- & одноместные - & 900 руб. / & душевая, телевизор с & вызов такси
\end{tabular} фортабельных номера, $\quad$ семиместные оснащенных всей необходимой мебелью ми, Wi-Fi

Гостиница «Восток», ул. Восточная, 22. Гостиница находится в 3 км от центра города и в 5 км от аэропорта

\begin{tabular}{|l|l|l|l|l}
\hline $\begin{array}{l}\text { гостиница предлагает } \\
12 \text { уютных номеров со } \\
\text { всей необходимой } \\
\text { мебелью }\end{array}$ & $\begin{array}{l}\text { одноместные, } \\
\text { двухместные }\end{array}$ & $\begin{array}{l}1000 \text { руб. / } \\
\text { сутки }\end{array}$ & $\begin{array}{l}\text { холодильник, СВЧ, } \\
\text { душ, Wi-Fi, парковка, } \\
\text { телевизор }\end{array}$ & вызов такси \\
\hline
\end{tabular}

Мини-гостиница «На Сибирском», пер. Сибирский, 11. Гостиница находится в 6 км от аэропорта и в шаговой доступности от центра города

\begin{tabular}{|l|l|l|l|l}
\hline $\begin{array}{l}\text { к услугам гостей } 7 \text { уют- } \\
\text { ных номеров со всей } \\
\text { необходимой мебелью }\end{array}$ & $\begin{array}{l}\text { двухместные, } \\
\text { трехместные }\end{array}$ & $\begin{array}{l}1500 \text { руб. / } \\
\text { сутки }\end{array}$ & $\begin{array}{l}\text { душ, телевизор, } \\
\text { Wi-Fi, парковка }\end{array}$ & вызов такси \\
\hline
\end{tabular}

Гостиница «Фортуна», ул. Кирова, 44. Гостиница находится в 5 км от центра города и в 10 км от аэропорта

\begin{tabular}{l|l|l|l|l}
$\begin{array}{l}\text { к услугам гостей } 9 \text { ком- } \\
\text { фортабельных номеров, } \\
\text { оснащенных всей } \\
\text { необходимой мебелью }\end{array}$ & $\begin{array}{l}\text { двухместные, } \\
\text { трехместные }\end{array}$ & $\begin{array}{l}1500 \text { руб. / } \\
\text { сутки }\end{array}$ & $\begin{array}{l}\text { душ, телевизор, } \\
\text { Wi-Fi, парковка }\end{array}$ & вызов такси \\
\hline
\end{tabular}




\begin{tabular}{|c|c|c|c|c|}
\hline Краткое описание & $\begin{array}{c}\text { Категория } \\
\text { номеров }\end{array}$ & $\begin{array}{c}\text { Минимальная } \\
\text { стоимость } \\
\text { номера }\end{array}$ & $\begin{array}{l}\text { Услуги, входящие } \\
\text { в стоимость номера }\end{array}$ & $\begin{array}{c}\text { Дополнительные } \\
\text { услуги }\end{array}$ \\
\hline \multicolumn{5}{|c|}{$\begin{array}{l}\text { Гостиница «Эконом-класс», ул. Студенческая } 3 B \text {, корп. 2. Гостиница находится в } 3 \text { км от аэропорта и в } \\
3 \text { км от центра города, в } 5 \text { минутах ходьбы от «Югра-Экспо» и от «Центра развития теннисного спорта» }\end{array}$} \\
\hline $\begin{array}{l}\text { гостиница предлагает } \\
\text { к услугам гостей } 16 \text { уют- } \\
\text { ных комнат }\end{array}$ & $\begin{array}{l}\text { четырехместные } \\
\text { - шестиместные }\end{array}$ & $\begin{array}{l}500 \text { руб. / } \\
\text { сутки }\end{array}$ & $\begin{array}{l}\text { телевизор, холодиль- } \\
\text { ник, кухня, Wi-Fi, } \\
\text { СВЧ, душевая, } \\
\text { парковка }\end{array}$ & вызов такси \\
\hline \multicolumn{5}{|c|}{$\begin{array}{l}\text { Хостел «Сибирь», ул. Кирова, } 54 \\
\text { Гостиница находится в } 5 \text { км от центра города и в } 10 \text { км от аэропорта }\end{array}$} \\
\hline $\begin{array}{l}\text { к услугам гостей } 6 \text { ком- } \\
\text { фортабельных номеров, } \\
\text { оснащенных всей } \\
\text { необходимой мебелью }\end{array}$ & $\begin{array}{l}\text { одноместные, } \\
\text { двухместные }\end{array}$ & $\begin{array}{l}700 \text { руб. / } \\
\text { сутки }\end{array}$ & $\begin{array}{l}\text { телевизор, Wi-Fi, } \\
\text { душевая, парковка }\end{array}$ & вызов такси \\
\hline
\end{tabular}

Анализ хостелов г. Ханты-Мансийска по таким параметрам, как категория номеров, минимальная стоимость, предоставляемые услуги, позволяет сделать вывод о том, что определенная ценовая политика на предприятиях гостиничного бизнеса Ханты-Мансийска отсутствует. Так, в ходе исследования установлено, что минимальная стоимость услуг не зависит от места расположения хостела или мини-гостиницы относительно центра города, а также от объема предоставляемых услуг в номере, в том числе дополнительных услуг. Возможно, данная ситуация обусловлена отсутствием в структурных подразделениях предприятий гостиничного бизнеса муниципального образования службы маркетинга, а также небольшим количеством консалтинговых организаций, осуществляющих деятельность на территории Югры и специализирующихся на выработке ценовой политики. Минимальная оплата суточного проживания в хостеле Ханты-Мансийска по состоянию на 01.04.2018 составила 390 руб., максимальный размер оплаты услуг хостела составляет 1500 руб. С учетом изложенного средний размер оплаты суточного проживания в хостеле, расположенном на территории муниципального образования, составил 945 руб.

Анализ уровня конкурентоспособности на рынке хостелов города Ханты-Мансийска с применением метода SWOT-анализа представлен в таблице $2^{2}$.

\section{Заключение}

К преимуществам ниши хостелов относятся растущий спрос на услуги подобного рода; широкая целевая аудитория; небольшие затраты для входа в бизнес; небольшое число конкурентов, осуществляющих деятельность в указанной сфере в г. Ханты-Мансийске. Недостатки тоже имеют место быть, среди них необходимость соблюдения значительного числа требований, установленных в ГОСТах и иных нормативных правовых актах; подготовка разрешительных документов; необходимость поиска помещения, высокие затраты на приобретение или аренду помещения.

Учитывая изложенное, проведенное исследование рынка хостелов Ханты-Мансийска позволяет сформулировать следующие рекомендации для предпринимателей, осуществляющих деятельность на территории муниципального образования в сфере гостиничного бизнеса:

- ниша рынка хостелов характеризуется невысоким уровнем конкуренции, в связи с этим открытие бизнеса в данной сфере представляется весьма перспективным направлением вложения средств;

- при открытии бизнеса необходимо строго соблюдать установленные законодательством требования (ГОСТ Р 56184-2014 «Услуги средств размещения: общие требования к хостелам», введенный в действие приказом Федерального агентства по техническому регулированию и метрологии от 23.10.2014 № 1393-ст);

- особое внимание следует уделить размещению хостела недалеко от центрального района или вблизи мест культурного отдыха и спортивных объектов;

- услуги хостела могут стать весьма востребованными не только среди путешественников и туристов, но и среди работников, осуществляющих трудовую деятельность вахтовым и сезонным методом;

- стоимость суточного размещения 1 постояльца не должна превышать 945 руб. (средний размер суточного размещения в хостеле Ханты-Мансийска);

- помимо основных услуг, входящих в стоимость размещения в хостеле, необходимо предоставить

\section{${ }^{2}$ То же.}


потребителям широкий спектр дополнительных платных услуг (трансфер, аренда автомобиля, кабельное телевидение, услуги Wi-Fi, услуги парикмахерской, тренажерного зала, прачечной, столовой и др.);
- особый акцент при проектировании бизнеса должен быть сделан на номерной фонд хостела (уровень комфортности номеров, обширность номерного фонда), а также на качество предоставляемых персоналом хостела услуг.

Таблица 2. SWOT-анализ уровня конкурентоспособности на рынке хостелов города Ханты-Мансийска Table 2. SWOT-analysis of the level of competitiveness in the market of hostels in Khanty-Mansiysk

\begin{tabular}{|c|c|c|c|c|}
\hline $\begin{array}{c}\text { Наименование } \\
\text { предприятия } \\
\text { сферы гостинич- } \\
\text { ного бизнеса }\end{array}$ & Сильные стороны & Слабые стороны & Возможности & Угрозы \\
\hline $\begin{array}{l}\text { Гостиница } \\
\text { «СДЮШОР», } \\
\text { ул. Калинина, } 1\end{array}$ & $\begin{array}{l}\text { - широкий спектр } \\
\text { дополнительных услуг, } \\
\text { предоставляемых } \\
\text { гостиницей; } \\
\text { - самая низкая в городе } \\
\text { стоимость суточного раз- } \\
\text { мещения постояльцев; } \\
\text { - удачное расположение } \\
\text { относительно центра } \\
\text { города }\end{array}$ & $\begin{array}{l}\text { - невысокое качество } \\
\text { предоставляемых услуг } \\
\text { в номере (в стоимость } \\
\text { номера входит только } \\
\text { предоставление телевизи- } \\
\text { онного вещания и аренда } \\
\text { холодильника); } \\
\text { - исключительная } \\
\text { ориентация услуг на } \\
\text { определенную категорию } \\
\text { граждан - спортсменов }\end{array}$ & $\begin{array}{l}\text { - необходимость } \\
\text { расширения спектра } \\
\text { услуг, входящих } \\
\text { в стоимость номера } \\
\text { (услуги Wi-Fi, CBЧ, } \\
\text { парковка, кабель- } \\
\text { ное телевидение, } \\
\text { трансфер); } \\
\text { - расширение } \\
\text { категорий граждан, } \\
\text { которым предостав- } \\
\text { ляется услуга по } \\
\text { размещению }\end{array}$ & $\begin{array}{l}\text { - отсутствие } \\
\text { предоставле- } \\
\text { ния инно- } \\
\text { вационных } \\
\text { услуг }\end{array}$ \\
\hline $\begin{array}{l}\text { Хостел «Черемуи- } \\
\text { кин Лог», } \\
\text { ул. Объездная, 39/2 }\end{array}$ & $\begin{array}{l}\text { - приемлемая цена раз- } \\
\text { мещения постояльцев, } \\
\text { ниже среднерыночной; } \\
\text { - самый широкий } \\
\text { спектр услуг в городе, } \\
\text { входящих в стоимость } \\
\text { номера; } \\
\text { - предоставление инно- } \\
\text { вационных услуг, обеспе- } \\
\text { чивающих комфортные } \\
\text { условия пребывания; } \\
\text { - благоприятное распо- } \\
\text { ложение относительно } \\
\text { мест культурного отдыха }\end{array}$ & $\begin{array}{l}\text { - высокий уровень } \\
\text { загруженности номеров } \\
\text { ввиду высокого спроса } \\
\text { на услуги }\end{array}$ & $\begin{array}{l}\text { - необходимость } \\
\text { расширения спектра } \\
\text { дополнительных } \\
\text { платных услуг }\end{array}$ & $\begin{array}{l}\text { - наиболее } \\
\text { стабильное } \\
\text { положение на } \\
\text { рынке хосте- } \\
\text { лов Ханты- } \\
\text { Мансийска, } \\
\text { необхо- } \\
\text { димость } \\
\text { сохранения } \\
\text { позиции ли- } \\
\text { дера на рынке } \\
\text { гостиничных } \\
\text { услуг }\end{array}$ \\
\hline $\begin{array}{l}\text { Гостиница } \\
\text { «Светлая», } \\
\text { ул. Светлая, } 24\end{array}$ & $\begin{array}{l}\text { - гостиница имеет боль- } \\
\text { шой номерной фонд; } \\
\text { - приемлемая цена раз- } \\
\text { мещения, не превышаю- } \\
\text { щая среднюю стоимость } \\
\text { суточного размещения }\end{array}$ & $\begin{array}{l}\text { - удаленность гости- } \\
\text { ницы от центра города } \\
\text { и мест культурного } \\
\text { отдыха }\end{array}$ & $\begin{array}{l}\text { - необходимость } \\
\text { расширения спектра } \\
\text { дополнительных } \\
\text { платных услуг } \\
\text { (например, платной } \\
\text { аренды автомобиля) }\end{array}$ & $\begin{array}{l}\text { - вероят- } \\
\text { ность падения } \\
\text { спроса на } \\
\text { услуги ввиду } \\
\text { удаленности } \\
\text { от центра } \\
\text { города и мест } \\
\text { культурного } \\
\text { отдыха }\end{array}$ \\
\hline $\begin{array}{l}\text { Гостиница } \\
\text { «Восток», } \\
\text { ул. Восточная, } 22\end{array}$ & $\begin{array}{l}\text { - значительное число } \\
\text { услуг, входящих в стои- } \\
\text { мость проживания }\end{array}$ & $\begin{array}{l}\text { - цена услуг несколько } \\
\text { завышена по сравнению } \\
\text { со средней стоимостью } \\
\text { суточного размеще- } \\
\text { ния в хостелах города } \\
\text { Ханты-Мансийска; } \\
\text { - гостиница имеет не- } \\
\text { большой номерной фонд; } \\
\text { - удаленность гости- } \\
\text { ницы от центра города } \\
\text { и мест культурного } \\
\text { отдыха }\end{array}$ & $\begin{array}{l}\text { - необходимость } \\
\text { пересмотра це- } \\
\text { новой политики } \\
\text { предприятия; } \\
\text { - необходимость } \\
\text { расширения спектра } \\
\text { дополнительных } \\
\text { платных услуг } \\
\text { (например, платной } \\
\text { аренды автомобиля) }\end{array}$ & $\begin{array}{l}\text { - вероят- } \\
\text { ность падения } \\
\text { спроса на } \\
\text { услуги ввиду } \\
\text { удаленности } \\
\text { от центра } \\
\text { города и мест } \\
\text { культурного } \\
\text { отдыха и вы- } \\
\text { сокой цены на } \\
\text { услуги }\end{array}$ \\
\hline
\end{tabular}




\begin{tabular}{|c|c|c|c|c|}
\hline $\begin{array}{c}\text { Наименование } \\
\text { предприятия } \\
\text { сферы гостинич- } \\
\text { ного бизнеса }\end{array}$ & Сильные стороны & Слабые стороны & Возможности & Угрозы \\
\hline $\begin{array}{l}\text { Мини-гостиница } \\
\text { «На Сибирском», } \\
\text { пер. Сибирский, } 11\end{array}$ & $\begin{array}{l}\text { - удачное расположение } \\
\text { относительно центра } \\
\text { города; } \\
\text { - комфортные номера }\end{array}$ & $\begin{array}{l}\text { - цена услуг значи- } \\
\text { тельно завышена по } \\
\text { сравнению со средней } \\
\text { стоимостью суточного } \\
\text { размещения в хостелах } \\
\text { г Ханты-Мансийска; } \\
\text { - небольшой номерной } \\
\text { фонд }\end{array}$ & $\begin{array}{l}\text { - необходимость } \\
\text { пересмотра це- } \\
\text { новой политики } \\
\text { предприятия; } \\
\text { - необходимость } \\
\text { расширения спектра } \\
\text { дополнительных } \\
\text { платных услуг } \\
\end{array}$ & $\begin{array}{l}\text { - веро- } \\
\text { ятность } \\
\text { значительно- } \\
\text { го падения } \\
\text { спроса на } \\
\text { услуги ввиду } \\
\text { завышенной } \\
\text { цены }\end{array}$ \\
\hline $\begin{array}{l}\text { Гостиница } \\
\text { «Фортуна», } \\
\text { ул. Кирова, } 44\end{array}$ & - комфортные номера & $\begin{array}{l}\text { - удаленное расположе- } \\
\text { ние относительно центра } \\
\text { города и мест отдыха; } \\
\text { - цена услуг значи- } \\
\text { тельно завышена по } \\
\text { сравнению со средней } \\
\text { стоимостью суточного } \\
\text { размещения в хостелах } \\
\text { г. Ханты-Мансийска }\end{array}$ & $\begin{array}{l}\text { - необходимость } \\
\text { пересмотра це- } \\
\text { новой политики } \\
\text { предприятия; } \\
\text { - необходимость } \\
\text { расширения спектра } \\
\text { дополнительных } \\
\text { платных услуг }\end{array}$ & $\begin{array}{l}\text { - веро- } \\
\text { ятность } \\
\text { значительно- } \\
\text { го падения } \\
\text { спроса на } \\
\text { услуги ввиду } \\
\text { завышенной } \\
\text { цены }\end{array}$ \\
\hline $\begin{array}{l}\text { Гостиница } \\
\text { «Эконом-класс», } \\
\text { ул. Студенческая } \\
\text { 3В, корп. } 2\end{array}$ & $\begin{array}{l}\text { - приемлемая цена раз- } \\
\text { мещения, не превышаю- } \\
\text { щая среднюю стоимость } \\
\text { суточного размещения; } \\
\text { - благоприятное распо- } \\
\text { ложение относительно } \\
\text { спортивных объектов }\end{array}$ & $\begin{array}{l}\text { - удаленное расположе- } \\
\text { ние относительно центра } \\
\text { города; } \\
\text { - ориентация услуг на } \\
\text { определенную категорию } \\
\text { граждан - спортсменов }\end{array}$ & $\begin{array}{l}\text { - расширения спек- } \\
\text { тра услуг, входящих } \\
\text { в стоимость номера } \\
\text { (трансфер); } \\
\text { - расширение } \\
\text { категорий граждан, } \\
\text { которым предостав- } \\
\text { ляется услуга по } \\
\text { размещению }\end{array}$ & $\begin{array}{l}\text { отсутствие } \\
\text { предоставле- } \\
\text { ния инноваци- } \\
\text { онных услуг }\end{array}$ \\
\hline $\begin{array}{l}\text { Хостел «Сибирь», } \\
\text { ул. Кирова, } 54\end{array}$ & $\begin{array}{l}\text { - приемлемая цена раз- } \\
\text { мещения, не превышаю- } \\
\text { щая среднюю стоимость } \\
\text { суточного размещения }\end{array}$ & $\begin{array}{l}\text { - удаленное расположе- } \\
\text { ние относительно центра } \\
\text { города; } \\
\text { - небольшой номерной } \\
\text { фонд }\end{array}$ & $\begin{array}{l}\text { - необходимость } \\
\text { расширения спектра } \\
\text { дополнительных } \\
\text { платных услуг }\end{array}$ & $\begin{array}{l}\text { - отсутствие } \\
\text { предоставле- } \\
\text { ния инно- } \\
\text { вационных } \\
\text { услуг }\end{array}$ \\
\hline
\end{tabular}

\section{Литература}

1. Старкова Г. П., Мартышенко Н. С. Малый бизнес в сфере гостиничного предпринимательства в Приморском крае // Российское предпринимательство. 2012. № 24. С. 243-249.

2. Базикян С. А. Роль региональных брендов в накоплении символического капитала места (на примере Великого Новгорода) // Вопросы теории и практики журналистики. 2017. Т. 6. № 4. С. 592-602. DOI: 10.17150/2308-6203.2017.6(4).592-602

3. Tyaglov S. G., Kushnarenko T. V., Khokhlov A. A., Qeropyan M. A. The development of cluster relations within the state and business structures in terms of strategy of non-primary sector import-substitution // European Research Studies Journal. 2017. № 1. P. 198-207.

4. Назаркина В. А., Штейнгольц Б. И. Особенности потребительского спроса в гостиничной сфере // Наука о человеке: гуманитарные исследования. 2014. № 2. С. 122-126.

5. Ларионова А. А. Современные тренды и перспективы развития гостиничного бизнеса в Российской Федерации // Региональная экономика: теория и практика. 2015. № 23. С. 43-53.

6. Лелека В. В., Соковнина Н. В. Хостелы как перспективная тенденция развития гостиничного бизнеса // Иннов: электронный научный журнал. 2017. № 1. Режим доступа: http://www.innov.ru/science/ economy/khostely-kak-perspektivnaya-tendents// (дата обращения: 05.04.2018).

7. Козырева О. А. Туризм 2015: мировые тренды // Вестник Российской международной академии туризма. 2014. № 4. С. 3-7.

8. Кукушкина А. Г. Хостел как центр детско-юношеского образовательного туризма: педагогизация среды // Вестник Новгородского государственного университета. 2016. № 2. С. 63-66.

9. Салманова И. П. Основные аспекты управления социальными гостиницами в гостиничном бизнесе // Вестник Российского университета дружбы народов. 2012. № 2. С. 112-121. 
10. Духовная Л. Л. Роль и значение хостелов в процессе повышения привлекательности туристской дестинации на примере г. Москвы // Сервис в России и за рубежом. 2014. № 2. C. 17-23. DOI: 10.12737/3583

11. Зинурова Р. И., Бардасова Э. В. Приоритетные направления организации и развития малых предприятий сферы услуг для начинающих бизнесменов // Вестник экономики, права и социологии. 2015. № 3. С. 42-44.

\title{
THE DEVELOPMENT OF THE HOSTEL MARKET AS A PROMISING AREA OF SMALL BUSINESS Irina V. Takmasheva ${ }^{a,}{ }^{(I D}$; Sergey G. Tyaglov ${ }^{b}$
}

\author{
${ }^{a}$ Ugra State University, 16, Chekhov St., Khanty-Mansiysk, Russia, 628012 \\ ${ }^{b}$ Rostov State Economic University, 69, Bolshaya Sadovaya St., Rostov-on-Don, 344002 \\ @I_Takmasheva@ugrasu.ru \\ ${ }^{I D}$ https://orcid.org/0000-0002-7422-2744
}

Received 03.11.2018. Accepted 26.11.2018.

Keywords: hotel business, competition, pricing, tourism, services

\begin{abstract}
The research features the Khanty-Mansiysk hostel market as a promising area of small business. The main objective of the study is to develop practical recommendations for the opening of hostels in the city of Khanty-Mansiysk. To achieve this goal, the following problem issues were studied: foreign experience in the development of hostel market, evaluation of supply and demand for hotel business in Khanty-Mansiysk, pricing in the hotel services market, and business climate for the development of the hostel market. The authors used the methods of statistical and comparative analysis, special methods of economic analysis, as well as the method of strategic planning SWOT-analysis. As a result of the research, the authors formulated proposals for the opening of hostels in Khanty-Mansiysk. The recommendations can be used by entrepreneurs engaged in the local hotel business. The proposals can also be useful to Khanty-Mansiysk administration in developing a strategy for the social and economic development of the municipality.
\end{abstract}

For citation: Takmasheva I. V., Tyaglov S. G. Razvitie rynka khostelov kak perspektivnoe napravlenie malogo biznesa [The Development of the Hostel Market as a Promising Area of Small Business]. Bulletin of Kemerovo State University. Series: Political, Sociological and Economic Sciences, no. 4 (2018): 137-144. DOI: 10.21603/25003372-2018-4-137-144

\section{References}

1. Starkova G. P., Martyshenko N. S. Malyi biznes v sfere gostinichnogo predprinimatel'stva v Primorskom krae [Small business in the sphere of hotel business in Primorsky Krai]. Rossiiskoe predprinimatel'stvo = Russian Entrepreneurship, no. 24 (2012): 243-249.

2. Bazikyan S. A. Rol' regional'nykh brendov v nakoplenii simvolicheskogo kapitala mesta (na primere Velikogo Novgoroda) [The role of regional brands in the accumulation of the symbolic capital of the place (on the example of Veliky Novgorod)]. Voprosy teorii i praktiki zhurnalistiki = Questions of theory and practice of journalism, 6, no. 4 (2017): 592-602. DOI: 10.17150/2308-6203.2017.6(4).592-602

3. Tyaglov S. G., Kushnarenko T. V., Khokhlov A. A., Qeropyan M. A. The development of cluster relations within the state and business structures in terms of strategy of non-primary sector import-substitution. European Research Studies Journal, 20, no. 1 (2017): 198-207.

4. Nazarkina V. A., Shteingolts B. I. Osobennosti potrebitel'skogo sprosa v gostinichnoi sfere [Characteristics of consumer demand in the hotel sphere]. Nauka o cheloveke: gumanitarnye issledovaniia = Science of man: humanitarian research, no. 2 (2014): 122-126.

5. Larionova A. A. Sovremennye trendy i perspektivy razvitiia gostinichnogo biznesa v Rossiiskoi Federatsii [Modern trends and prospects for the development of hotel business in the Russian Federation]. Regional'naia ehkonomika: teoriia i praktika = Regional economy: theory and practice, no. 23 (2015): 43-53. 
6. Leleka V. V., Sokovnina N. V. Khostely kak perspektivnaia tendentsiia razvitiia gostinichnogo biznesa [Hostels as a promising trend in the development of hotel business]. Innov: ehlektronnyi nauchnyi zhurnal = Innov: electronic scientific journal, no. 1 (2017). Available at: http://www.innov.ru/science/economy/khostelykak-perspektivnaya-tendents// (accessed 05.04.2018).

7. Kozyreva O.A. Turizm 2015: mirovye trendy [Tourism 2015: world trends]. Vestnik Rossiiskoi mezhdunarodnoi akademii turizma = Bulletin of the Russian International Academy of Tourism, no. 4 (2014): 3-7.

8. Kukushkina A. G. Khostel kak tsentr detsko-iunosheskogo obrazovatel'nogo turizma: pedagogizatsiia sredy [The hostel as the center of children's and youthful educational tourism: the pedagogy of the environment]. Vestnik Novgorodskogo gosudarstvennogo universiteta = Bulletin of Novgorod State University, no. 2 (2016): 63-66.

9. Salmanova I. P. Osnovnye aspekty upravleniia social'nymi gostinitsami v gostinichnom biznese [The main aspects of management of social hotels in the hotel business]. Vestnik Rossiiskogo universiteta druzhby narodov = Bulletin of the Russian University of Friendship of Peoples, no. 2 (2012): 112-121.

10. Dukhovnaya L. L. Rol' i znachenie khostelov v protsesse povysheniia privlekatel'nosti turistskoi destinatsii na primere g. Moskvy [The role and importance of hostels in the process of increasing the attractiveness of tourist destination on the example of Moscow]. Servis v Rossii i za rubezhom $=$ Service in Russia and abroad, no. 2 (2014): 17-23. DOI: $10.12737 / 3583$

11. Zinurova R. I., Bardasova E. V. Prioritetnye napravleniia organizatsii i razvitiia malykh predpriyatii sfery uslug dlia nachinaiushchikh biznesmenov [Priority directions of organization and development of small enterprises in the sphere of services for novice businessmen]. Vestnik ekonomiki, prava $i$ sociologii $=$ Bulletin of Economics, Law and Sociology, no. 3 (2015): 42-44. 